\title{
The impact of urban sprawl on the heritage areas through the urban fabric of cities
}

\author{
A. El Menchawy, S. S. Aly \& M. A. Hakim \\ Arab Academy for Science and Technology, \\ Architectural Engineering and Environmental Design Department, \\ Alexandria, Egypt
}

\begin{abstract}
Historical sites are the economic, cultural and social drivers for a dynamic and sustainable environment. They constitute an integral part of nations' history, identity and regional diversity. Small and medium-sized historical sites with their outstanding built cultural heritage strongly shape the urban landscapes and form the backbone for a balanced and polycentric settlement structure.

Historical sites face many challenges, like accelerating globalization, structural, social and demographic changes as well as environmental problems and urban growth. As urban growth is a double faced process it is the concentration of population in urban areas due to supplied services that are missing in rural areas, at the same time it is a decline of socio-economic areas agglomerations. This increase in population happens due to the concentration of economic activity, which is an important determinant, and the result of urbanization. This results in introducing unbalanced trends which destroys human cohesion and builds social exclusion in cities and regions. Through urbanization, people ignore their identities and traditions seeking adequate services and a better lifestyle leading to the disappearance of existing urban fabric that creates an undefined urban pattern. The right balance between restoring and preserving unique cultural heritage has to be set to enable futureproof urban development. Urban growth affects the efficiency of production and economic growth, and the way agents interact and live in cities. Understanding its implications and causes has captured the interest of economists, architects and urban planners in the past and deserves to continue doing so in the future.

The research aims to extract a set of urban guidelines to cope with the development process with respect to the identity and character of the place and to
\end{abstract}


highlight the importance of historical sites, which creates job opportunities, and help to raise the socio-economic level of the society

Keywords: historical sites, heritage, identity, architectural style, urban conservation.

\section{Introduction}

Cities and towns act as catalyst for cultural, social and economic development. Half of the world's population already lived in urban settlement. Historical sites represent the heart of the cities which play a very important role in creating a stimulating and economically attractive environment for inhabitants. The development of these sites is an integral part of societies that comprises historic buildings, urban spaces and people using them. Preserving this cultural identity of the city through making the necessary changes for development while maintaining current qualities is one of the main goals of the paper.

\subsection{Problem statement}

Urbanization is the physical growth of urban areas because of global change. It is derived from Latin word "urbs" a term used by the Romans to a city. Thompson Warren has defined it as the movement of people from communities concerned chiefly or solely with agriculture to other communities generally larger whose activities are primarily centered in government, trade and manufacture. It is closely linked to modernization, industrialization and the sociological process of rationalization.

\subsubsection{Causes of urbanization}

Urbanization are affected by many factors mainly the key determinant of migration is the income differential between rural and urban regions. Migration is also affected by crop prices, landowning structures and changes in agricultural technologies. It is also influenced by other factors related to individual or household structures and survival strategies, and wider political, economic and social forces that are presented in the following:

- Higher standard of living that is missing in rural areas due to unpredictable weather conditions such as drought and floods, which can adversely affect their livelihood.

- Linkage to the global economy due to presence of new information technologies resulting in benefits are not equally shared among people.

- National government policies concerning migration, national investment in communications, transport infrastructure have profound impacts on the urban system.

- Creating a strong bond between communities due to culture exchanging. 


\section{Identifying heritage}

\subsection{Definition of heritage}

The property, attribute or immaterial possession inherited from ancestors. ICCROM team [1]. Therefore, heritage is:

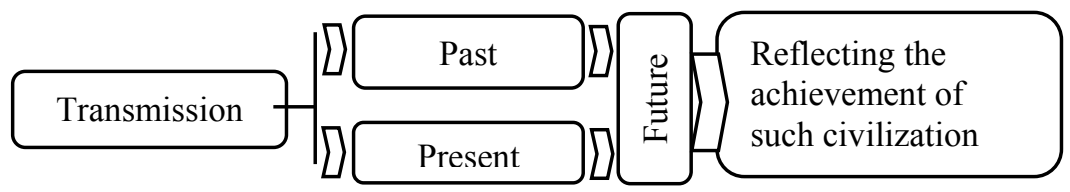

Figure 1: Heritage connecting past with present for a better future.

Heritage has many different ways and forms which are classified as follows:

\subsubsection{Cultural heritage or "national heritage"}

It is the creative expression of people's existence in the past represented through the legacy of physical artifacts and intangible attributes that are inherited from past generations maintained in the present and bestowed for the benefit of future generations.

\subsubsection{Cultural heritage can be distinguished through two kinds}

2.1.2.1 Physical or "tangible heritage" Includes material heritage, which can be physically touched and considered worthy of preservation for future generations.

Tangible heritage in its meaning includes two types:

- Movable tangible heritage: Objects that can be moved easily from one place to another.

- Immovable tangible heritage: Buildings which cannot be removed from its place of origin.

2.1.2.2 Intangible cultural heritage Immaterial heritage, which means the practices, representations, expressions, knowledge, music, dance, theatre and religious ceremonies that, is transmitted from generation to generation in response to their environment, their interaction with nature provides them with sense of identity.

\subsubsection{Natural heritage}

Natural features consisting of physical, biological and geological formations or habitat of threatened plants or animal species, which are of outstanding universal value from the aesthetic or scientific point of view. 


\subsection{Importance of heritage}

- Conveys diverse messages and values that contribute to give a meaning to people's life.

- Represents the identity of a social group.

- Represents a vehicle for understanding the diversity of people and developing a policy for peace and mutual comprehension.

- A source of economic development.

\section{Identity}

\subsection{Definition of identity}

It is the collective aspect of the set of unique characteristics (behavioral or physical features) by which a thing or person is recognizable or known. Cultural identity: is a social process in which individuals participate in the context of changing historical conditions like historical reservoir [2].

Identity is defined as follows:

- It is the distinguishing character or condition of a person or a thing according to place within historically specific discourses.

\subsection{Reasons of fading of identity}

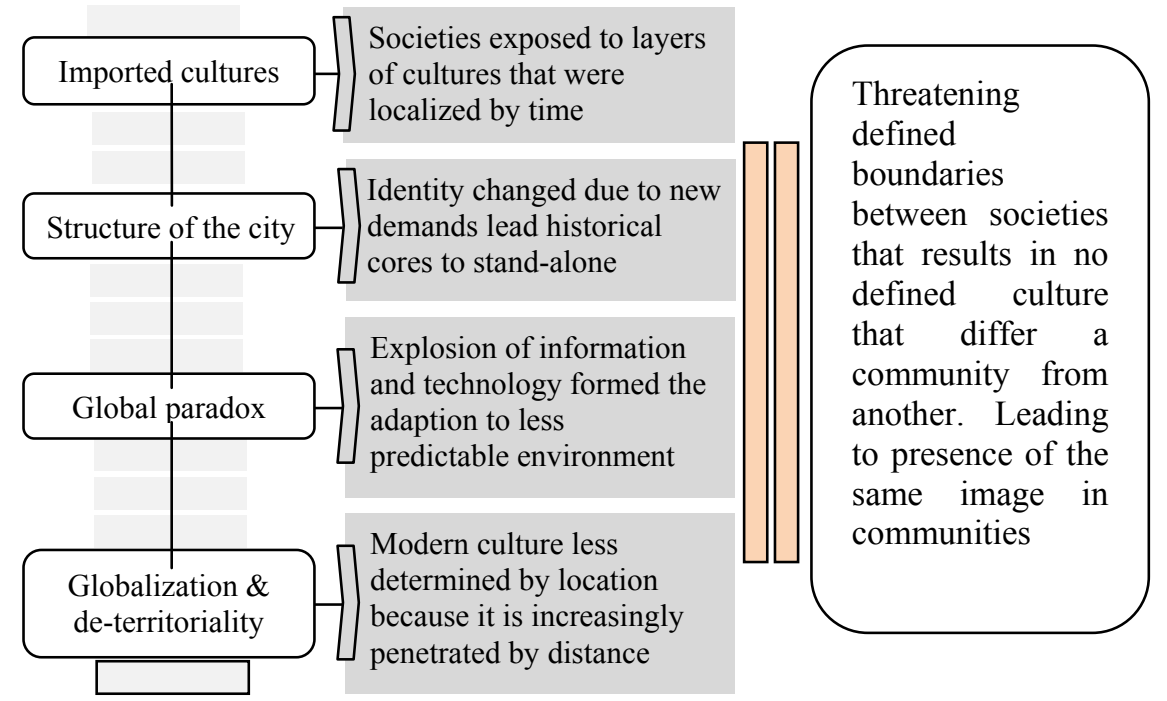

Figure 2: Factors affecting fading of identity. 


\subsection{Urban identity in the changing context of the city}

- The essential goal for future development of a good environment is identity. At the urban level, the environment should be such that it encourages people to express themselves and to become involved.

- City is always dynamic which includes an evolving process that can destroy and replace parts of it. This evolution is also significant in the creation of a sense of place (Okaty [3]).

\subsubsection{The significance of districts}

- The local urban context is considered, the district or quarter/neighborhood that is the identifying symbol both for the evaluation of the city, and for the new urban extension, and it is also fundamental for sustainable development.

- Considering the identity theme, the neighborhood is not seen as a means for participation but as a vehicle for strengthening the bonds between residents and their environment. In this context, topographical circumstances such as a dividing river or a green belt may significantly contribute to the formation of different districts.

- Since the identity of the neighborhood grows from the continuous relationship between the place and its residents, the neighborhood is expected to become its residents' cultural creation and at the same time a means for the preservation of the cultural continuity of the city.

\subsubsection{The role of public spaces}

Perception of the visual forms that provide the physical context for the public domain is very important. Public space is regarded as "the common ground where people carry out the functional and ritual activities that bind a community, whether in the normal routines of daily life or in periodic festivities" (Carr et al, 1992, p xi).

- It is the urban experience of places and spaces conceived to link people to vital social life. However, the perception of public domain is formed from the given information from the surrounding environment.

- The public domain extends from the streets, squares and parks to the buildings that enclose them, it makes the most important part of towns and cities (Madanipour [15]). Perhaps the best evidence for the vital importance of public urban spaces is historical.

- "The street": (Jacobs [16]), is an important critic of the urban forms: "Streets and their sidewalks, the main public places of a city, are its most vital organs". The optimum definition for a street is "an enclosed, three-dimensional space between two lines of adjacent buildings". However, nowadays the concept of street has been lost due to lack of three-dimensional qualities.

- "The square": it is most easily imaginable, and represents a goal for movement. It is determined by the same formal factors as the street, with the difference that the buildings are not the edge of the public space but it is the frame forming the overall image (Moughtin [4]). 


\section{Characteristics of Arab architecture and features driven from them}

"In researching the sources, the following principles can be distilled that will help give us an understanding of how man should address the environment: Stewardship of the Earth; Relationship with Nature; Relationship between Men; Justice; The Public Interest; Concern for the Poor and Weak; and, Individual Behavior" (Khan [5]).

\subsection{Design principles of the Arab City in broad terms}

\subsubsection{Natural law}

It is respecting natural circumstances as weather conditions and topography and adapting the built form and city plan with it. This principle resulted in concepts as the courtyard, terrace, narrow covered streets, and gardens (Saaoud [6]).

\subsubsection{Religious and cultural beliefs}

Religious beliefs and practices had an enormous effect forming the cultural life center for the Arab people, thus:

a) The Mosque is the central node for spatial and institutional hierarchies.

b) Town plan is of courtyard houses with narrow streets and cul-de-sacs separating public and private zones.

c) Economic activities and residential zones were separated to emphasize the separation of male and female user of space.

\subsubsection{Social principles}

The social organization of the urban society was based on social groupings sharing the same blood, ethnic origin and cultural perspectives. These were reflected in the concept of quarters known as Ahiaa (in the Mashraq) or Huma (in the Maghreb).

\subsection{Detailed principles and driven features}

\subsubsection{Form and climate}

Due to climate:

a) Natural architectural forms using appropriate local materials evolved to retain the coolness of night of the evening throughout the hot day.

b) Forms are designed to catch the cool wind when it blows.

c) The use of heavy, thick walls of mud, masonry or stone is for sufficient thermal resistance [7].

\subsubsection{The driven features}

The driven features are:

a) The openings of buildings are small windows placed for privacy and protection from the sun by the Mashrabeyya.

b) Inside court, forms are used, covered with colonnades and the rooms open onto the balconies overlooking the court allowing air to flow through the building in every room.

c) The planning of narrow streets between buildings shade throughout the day, cooling buildings walls and streets. 


\section{Case study: Turkish town space and society}

\subsection{Introduction}

"The design of town is design in four dimensions. A town provides a framework for change to meet the changing needs of those who live and work in it. local resources are discovered, exploited and worked out; industries rise and fall; populations ebb and flow, living standards change. Responsive to every nuance of demand, the city all the time adapts itself accordingly." "Middleton 1987:35."

\subsection{Location and physical setting of the Turkish town}

- Turkish town is situated to the west of the current Alexandria city.

- It occupies the isthmus separating the western (main) port and the eastern fishing port.

- The area is bordered by the sea on three sides, while the south ends with Alexandria's business district.

- It stretches about $1 \mathrm{~km}$ in the north-south direction and $800 \mathrm{~m}$ in the east-west direction.

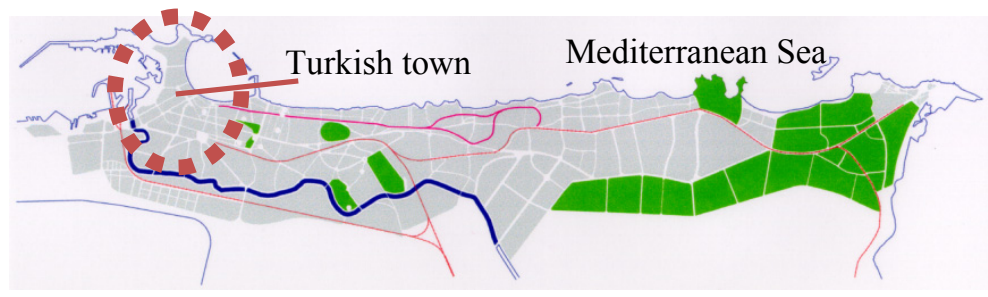

Figure 3: Map showing Turkish town in relation to Alexandria.

Through recent historical development of the city assert the dramatic pressures that are to be considered in order to deal with the problems of overloaded infrastructure, services, transport as well as the inevitable economic and commercial pressures resulting from its physical setting and the surrounding forces.

- A major thoroughfare (Al Corniche) borders the area, and to the south by Al Nasr Street; within these borders it is sliced into smaller zones by a group of main streets that belong to the late $19 \mathrm{c}$.

- Despite the various attempt for modernization, the traditional morphological outline of the area is still readily distinguishable.

\subsection{Historical background}

- The Turkish Town: was founded in 1517 with the start of the Turkish regime. This area was the only inhabited area until the early 19th century. It lies with its commercial activities at the neck between the two harbors the eastern and western harbors and outside the fortified walls of the Arab city. In the middle of 
the 17th century, Alexandria was described as a small village with two or three streets and a bazaar. In the period of 1630-1640 A.D. there were new developments based largely on the trade of Yemeni coffee beans exported to the ottoman provinces and Europe in addition to the textile manufacturing using silk, which was imported from Syria where $12 \%$ of population worked in this trade (Breccia [9]).

- Mohamed Ali constructed an access for Ras el Tin Palace (1817) which lies on the extreme west of the ancient island of Pharos, was provided by the enlarging and widening of Faranca Street.

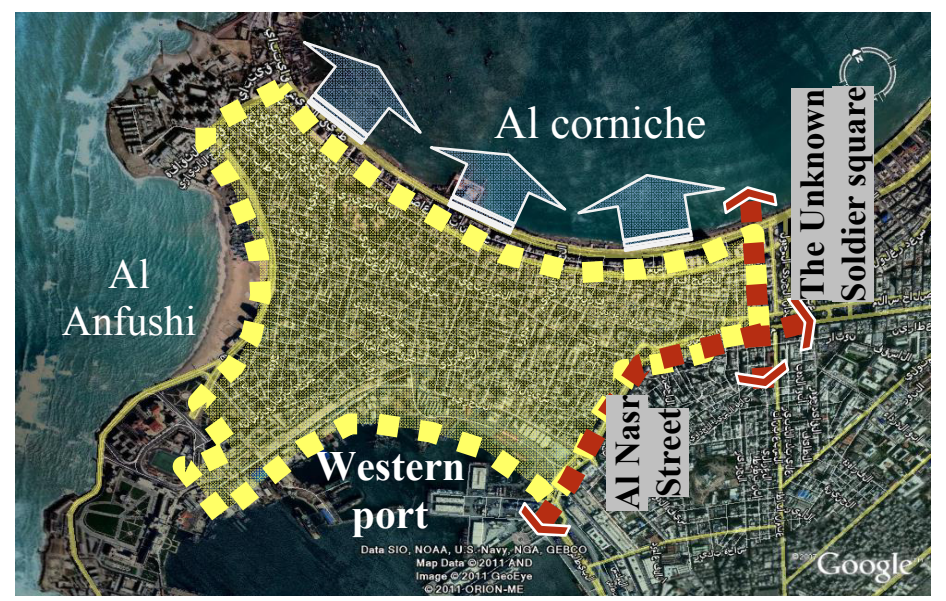

Figure 4: Google Earth showing the borders of Turkish town and the access to the town though two main streets $\mathrm{Al}$ corniche and $\mathrm{Al}$ Nasr Street.

\subsection{Architecture style of the area}

Despite the lack of documentation for the architectural history of the Turkish town it appears in the diversity of nature of the area, remains of style and state of the buildings has made it clear to establish the outline of the building development which have witnessed 4 stages of development, as shown in Table 1.

\subsection{Morphological analysis}

\subsubsection{Street pattern}

The general street pattern, even the modern parts have a certain degree of irregularity which is due to: the curved nature of its natural borders and obviously to the influence of the traditional urban pattern of the city. 
Table 1: $\quad$ Hierarchy in architectural style of Turkish town [10].

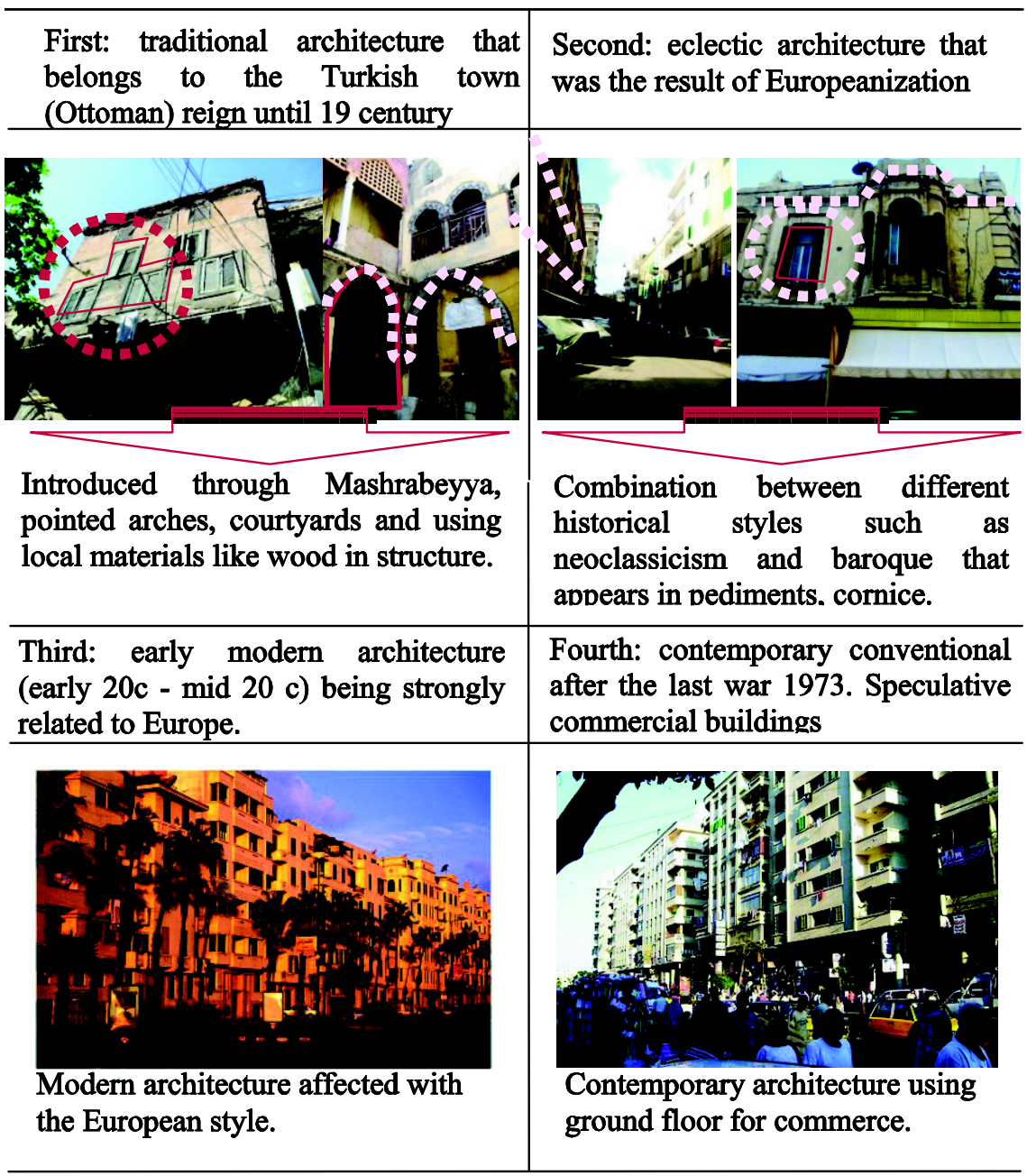

\subsubsection{The sequence of street pattern of Turkish town}

The sequence of street pattern of Turkish town can be illustrated as follows:

- Shariah: serves as the main street which links the area with other parts of the town which enclose shops. The width of the street allows for movement of carts.

- Harah: serves as a secondary street which is narrower than the former, mainly used as access both houses and smaller streets (Atfa or Zuqaq). These streets form the first community unit as the occupants of each Harah participate in a close social life and act as a big family. 
- Atfa: this kind of street serves as a link between the main street and the Harah. It is narrower than the Harah as it was designed to accommodate pedestrians as well as carrying animals.

- Zuqaq: a short dead end street which forms the last threshold of the sequence (Assem [11]).

Table 2: $\quad$ Representing different street patterns.

\begin{tabular}{|l|l|}
\hline $\begin{array}{l}\text { The intersection of these } \\
\text { streets is hardly to be at } \\
\text { a right angle. }\end{array}$ & $\begin{array}{l}\text { Pedestrians gain a rich } \\
\text { visual experience due } \\
\text { to irregularity of } \\
\text { streets. }\end{array}$
\end{tabular}
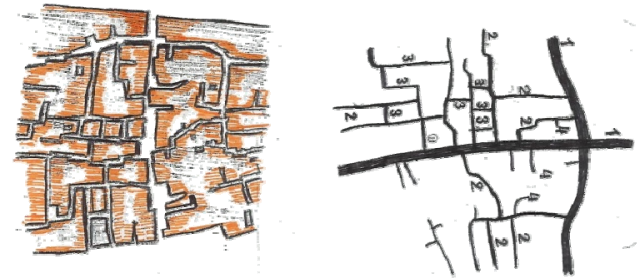

Figure 5: Representing the hierarchy of the street patterns of Turkish town.

\subsection{Land use and activities pattern}

To evaluate the economic pattern of the area:

- Over $60 \%$ of the working force of Al Gommrok is working in the district whilst $30 \%$ of 
- The overall working force in it comes from other areas these figures shows the potential for economic activities within the area, as it employs about $90 \%$ of its working force

- Those activities can be classified as the following fishing, commercial activities (retail forming the backbone of the economic structure they represent) $40 \%$, workshops represent $19 \%$ like furniture and metal, wholesale represents $11 \%$.

- Historical buildings the main buildings are (Al Shourbagy Mosque, Terrbana mosque, Abou Al Abbas mosque) (Wratten [12]).

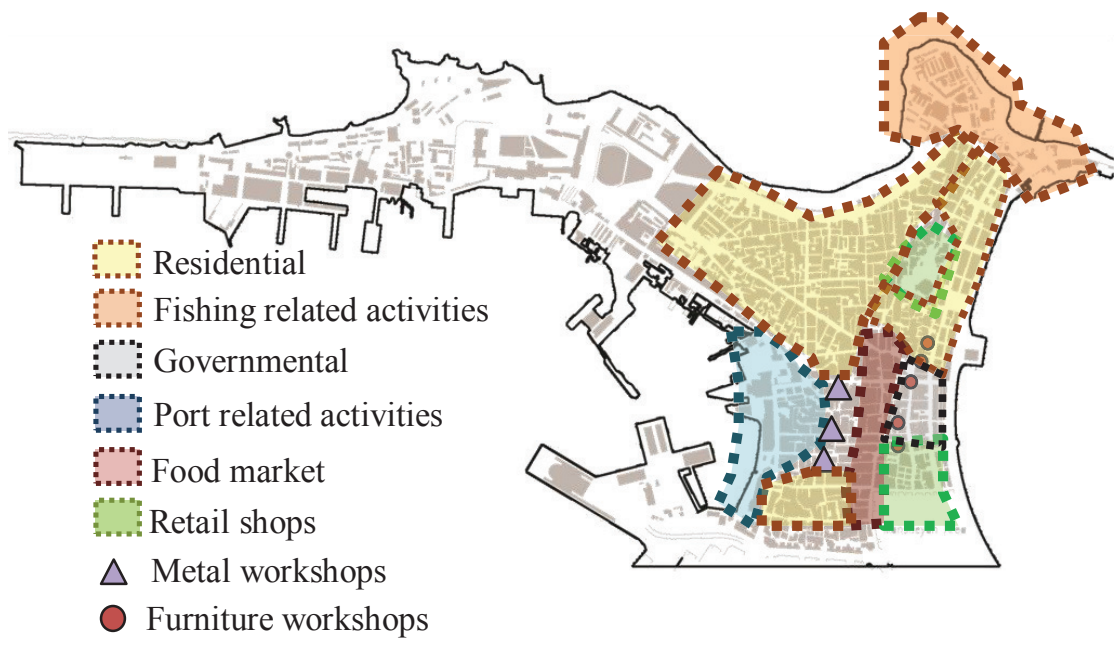

Figure 6: Land use of Turkish town. (See online for colour version of this figure.)

\subsection{Heights and building conditions}

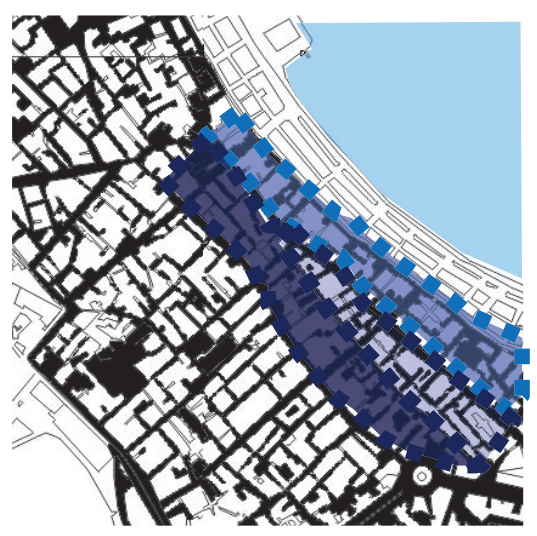

Figure 7: Sample in the Turkish town shows different heights of buildings. (See online for colour version.) 
- Represents building heights varies from 7 to 12 heights which is found behind the European residential building styles. As the building condition of these buildings varies are in good conditions (good structure system and building materials).

- $\square$ The height of buildings ranges from 2 to 3 floors maximum this is due to the structure (bearing walls with no foundation).

- The height at this area varies from 5 floors till 20 floor due to presence of different architectural style.

\subsection{S.W.O.T analysis}

\subsubsection{Strengths}

- Location of Turkish town near Qaiet Bay fort and bibliotheca Alexandria as shown in figure 8 , to create touristic trips connecting those attractive points with the Turkish town.

- Presence of historical buildings dating back to ottoman reign, which concentrate commercial and recreational activities.

- Hierarchy in walkways from pedestrian to vehicle streets.

- Historical buildings of Turkish town used ecological materials to adapt the environmental conditions of Arab cities such as limestone, marble and wood.

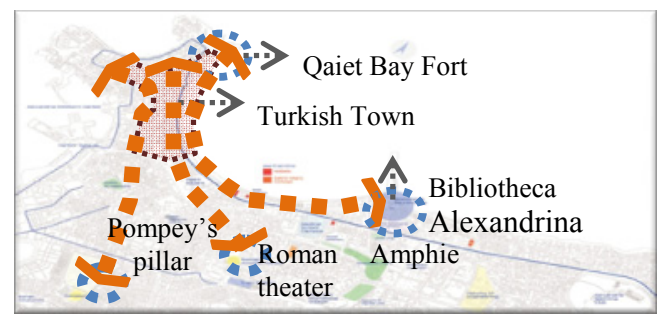

Figure 8: Representing development of Turkish town [13].

\subsubsection{Weakness}

- Due to the presence of historical monuments, dating back to the Turkish town that suffers from enormous threat the theme of the urban fabric represented nowadays as random scattering of different architectural styles.

- There were no themes in distribution of land use in the Turkish town as represented in the variety of uses placed there such as (industrial, commercial, residential, monumental and some governmental buildings).

- Lack of streetscape along the Turkish town such as (lighting fixtures, furniture, signs and garbage disposal) loosening the town its identity.

- Presence of deteriorating housing core which results from unrealistic urban planning.

- The absence of essential community facilities and services to fit the urban growth found in the site. 


\subsubsection{Opportunities}

- Monumental buildings are always a center of attraction whether for tourists or residents which appear in commercial and some industrial activities that are related with the identity of the place this creates job opportunities and help in raising socio economical level of inhabitants.

- Through observation the rate of movement of tourists is directly proportional to the activities located in historical sites which is one of the helpful things for tourism to let them explore such places carefully and understand different civilizations which encourages preserving the streets as it is according to their proportions.

- Rehabilitation of historical buildings to reuse it to help for upgrading the social life of inhabitants and make it easier for tourist to be introduced to the traditions of the place.

\subsubsection{Threats}

- High population density affects buildings' conditions accelerating its deterioration.

- Traffic and huge network of transportation results in vibration to the foundation of historical buildings.

- Bad infrastructure causing sanitation problems due to presence of slum areas that are not supported with the needed services.

- Underground water accelerates demolition of residential buildings due to insufficient services for urban development (Rankine [14]).

\section{Conclusions}

During recent decades, the rehabilitation and regeneration of historic centers has been increasingly recognized as an efficient tool for urban development, synthesizing cultural values with economic opportunities and benefits. The value of each historic building is not only in the appearance of individual elements, but also in the integrity of all its components as a unique product of the specific
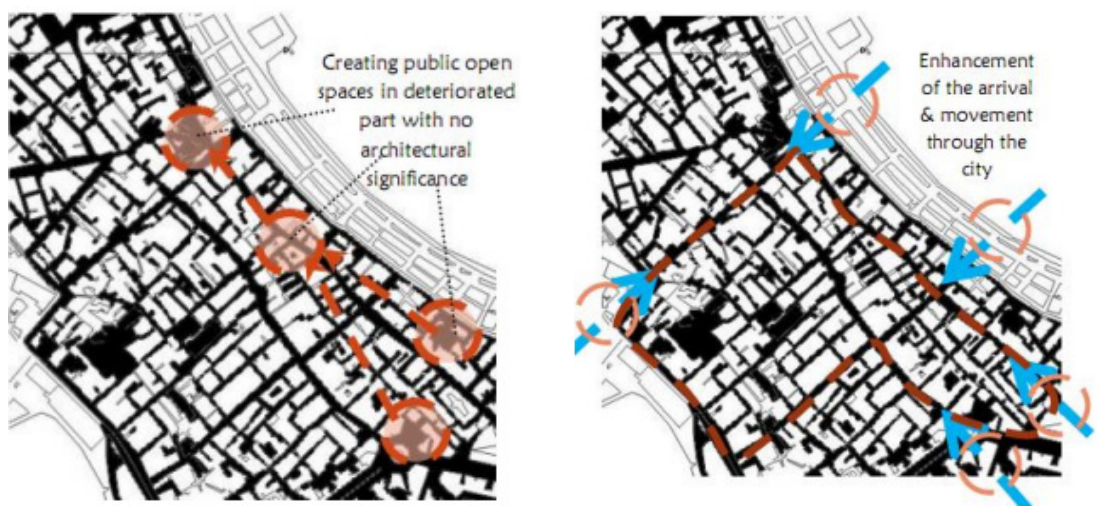

Figure 9: Solid and void map presenting future development. 
building technology of its time and place. Thus, the removal of the inner structures retaining only a façade does not satisfy conservation criteria.

Considerations of conservation in development should be seen not only in the light of preserving the built and natural environment, but also the fundamental elements of the social environment equally. Although each generation has an obligation to preserve and transmit the cultural and historic legacy it has inherited, it is not common to witness the destruction of historical or cultural amenities.

\section{Recommendations}

\subsection{Governmental regulations}

- Architectural style: The main squares which enclose the historical monuments of the Turkish town must represent a sequential hierarchy in architectural style to bringing back such spirit of Islamic city to the tourists.

- Materials: Regulations must be set to adopt using traditional materials and develop it to achieve ecological historical environment.

- Social conditions: Government regulations must set the rental law to be family renting to be appropriate for the space such as family of 5 persons with a maximum of 3 person/room due to deterioration of buildings.

\subsection{Urban planning}

- Land use: The main aim is conserving the main image of the Turkish town through its fabric so attraction points must be distributed along the streets of the Turkish town to attract tourist to walk through the city without feeling bored.

- Transportation movement: Appropriate parking must be supplied to facilitate tourism movement.

- Creating loading points for public transportation so as the residents living there could access easily to their home without hurting the historical buildings.

- There must be separation between pedestrian walks and public roads to facilitate the movement of the tourist in the Turkish town.

\subsection{Public awareness}

- Increasing the percentage of illiteracy in the Turkish town affecting the monuments badly this due to the ignorance of the importance of historical sites to the national income for societies.

- Raising the educational level of people to be effective and cooperative in the conservation process. 


\subsection{Improvement of cultural and social environment}

- Creating job opportunities through creating development projects such as attraction points for tourists since it is a focal point through emigrants or tourists.

- Raising public awareness of the inhabitants and introducing them the importance of historical sites.

\subsection{Public realm and open spaces}

- Greater emphasis needs to be given to the street and to the sequential network of pedestrian spaces if the city centre is to become more attractive to future users and investors.

- Creating more co-ordinate and seamlessly legible townscape, not only for pedestrians, but also for cyclists, drivers and public transport users.

- New and existing public spaces are to be linked by improved streetscape treatment. Public art, planting, lighting and water features will be incorporated into the new and enhanced spaces.

- Comfortable street level activity is important, both for civic and event purposes, but also to stimulate general footfall and a sense of public safety and vitality.

- The perception and visual dominance of the motor car needs to be mitigated to enhance the perception of pedestrian comfort.

\subsection{Built form and urban design}

- Promote more integrated, unified centre areas of historical character, scale and building lines, all of which create and reinforce the city block relationship.

- Focus on the growth of smaller scale cultural activity that reinforces the archaeological heritage of the area and provides opportunities for retail, cafe and restaurants that are consistent with the fabric, scale and character of the area.

- Active ground floor uses will be encouraged along main pedestrian routes to stimulate new investment and employment.

\section{References}

[1] ICCROM Team, Introducing Young People to the Protection of Heritage Sites and Historic Cities, A Practical Guide For School Teachers in The Arab Region, UNESCO, 1st edition, 2003

[2] Correa Ch., Exploring architecture in Islamic cultures1, Architecture and Identity, The Aga Khan Award for Architecture, Universiti Teknologi, Malaysia, p. 10-13, July 25-27, 1983

[3] Okaty D., The quest for urban identity in the changing context of the city, Eastern Mediterranean University, Faculty of Architecture, p.262, 2002

[4] Moughtin C., Urban Design, Street and Square, Oxford, Third edition, 2003 
[5] Khan F. The Islamic Environment: Can the Future Learn from the Past, In Toward an Architecture in the Spirit of Islam, The Aga Khan Award for Architecture, Philadelphia, 1978

[6] Saaoud R., Introduction to the Islamic city, Foundation for Science Technology and civilization, p.4, August 2002

[7] Ismail S., Faith and the Environment, In Space for Freedom, Butterworth Architecture, London, 1989 [8] Google Earth, Alexandria, Egypt, Modified by the researcher, 2011

[8] Jondent G., Atlas Historique De La Ville Et Des Prots D'Alexandrie, La societe Sultanieh De Geographie, 1921

[9] Breccia, Alexandria AD Egyptum: a guide to the ancient and modern town and to its Graeco-Roman Museum, Alexandria, 1922

[10] Jason D., Modern Islamic Architecture in Alexandria, Islamic Quarterly, Vol. 13, p. 183-191, 1969

[11] Assem M., Development and conservation with special reference to the Turkish town of Alexandria, Institute of advanced architectural studies University of York, 1993

[12] Wratten E., Gomrok Local Plan, Final report, Alexandria, 1985

[13] Alexandria's map, www.wikitravel.org/upload/shared//5/58/Map1-alex.jpg

[14] Rankine L., The planning problems and policies of Heritage coasts, 1976

[15] Madanipour, A., Design of Urban Space. Wiley, New York, p. 146, 1996

[16] Jacobs, J., The Death and Life of Great American Cities. Random House, New York, 1961 